\title{
Entre o real e o imaginário: a ficção literária como apreensão do mundo
}

\author{
Rui Uchoa Dornelas ${ }^{\mathrm{i}}$
}

\begin{abstract}
RESUMO
Uma das questões mais antigas e constantes na história da literatura diz respeito às relações que a arte literária é capaz de manter com a realidade objetiva. Nesse contexto, a tentativa de melhor definir a influência dessas relações no âmbito tanto da produção literária, quanto de sua recepção crítica se depara com a necessidade de revisar os mecanismos pelos quais, do imaginário ao texto literário, o mundo real é capaz de se tornar um mundo ficcional. É nesse intuito, portanto, que se delineia aqui um percurso de feição teórica, baseado na reflexão autores como Lukács, Sartre, Candido e Iser.
\end{abstract}

Palavras-chave: ficção; literatura; representação literária.

\begin{abstract}
One of the most ancient e constant issues within the realm of the literary history concerns the relationships established between the literary arts and their objective reality. Within this context, the attempt to define the influence exerted by those relationships on the spheres of literary production and its critical reception comes across the need to review the mechanisms by which, from the imaginary to the literary text, the actual world can become a fictional one. With that purpose, the present article develops a theoretical inquire based on the reflection of authors such as Lukács, Sartre, Candido and Iser.
\end{abstract}

Keywords: fiction; literature; literary representation.

Enquanto forma e linguagem constituídas a partir da necessidade de expressar certa visão de mundo, a literatura adquiriu roupagens e funções diversas no decorrer da história. De maneira análoga, se esse espectro varia de maneira heterogênea, não seria novidade distribuir os diversos momentos de seu curso produtivo entre a denotação inconteste de uma realidade determinada a priori e o desdobramento das vicissitudes

\footnotetext{
${ }^{\text {i }}$ Possui graduação em Medicina pela Universidade Federal de Pernambuco (2011) e mestrado em /Teoria da Literatura (2017), obtido junto ao Programa de Pós-Graduação em Letras da mesma instituição (PPGL-UFPE). Tem experiência nos estudos relacionados à mímesis, à ficção literária, bem como às relações estabelecidas entre as formas literárias e a realidade em acepção abrangente. rui.dornelas@gmail.com
} 
subjetivas diante de um mundo no qual, como diria Lukács (2009, p. 55), a "imanência do sentido à vida tornou-se problemática".

Não obstante, a diversidade formal e estética contida nesse lugar-comum descritivo, dois aspectos despontam de maneira marcante no curso histórico da literatura ocidental, discerníveis no interior de sua produção artística. Sejam eles: uma obstinação, como afirma Barthes (1996), em dar conta do real por meio da linguagem, atrelada à necessidade de estendê-la à experiência elou fruição estética do outro. Posto de outra maneira, não seria imprudente delimitar o conjunto dessa produção literária segundo a necessidade de produzir uma realidade de natureza textual e imaginativa, atrelada ao caráter comunicacional inerente à sua condição de gesto linguístico. Em resumo, uma literatura sempre às voltas com os contornos fronteiriços do imaginário, próprios à ficção, e de sua recepção estética, por meio da leitura.

Reducionista em seu pretenso universalismo, tal premissa não passa, no entanto, de um preâmbulo reflexivo, no intuito de apontar como a literatura se relaciona de maneira estreita, ainda que nem sempre em níveis evidentes, às contingências socioculturais que permeiam tanto a criação quanto a recepção de seu espólio artístico. Não é mais, portanto, do que um ponto de partida, na intenção de redimensionar os contornos iniciais das premissas que permeiam o sujeito em questão, descrito aqui como as relações empreendidas entre o real, o ficcional e o imaginário, circunscritas pelos diversos preceitos e categorias de seu contexto histórico.

\section{DADO, IMAGEM, PALAVRA: FICÇÃO E LITERATURA}

Em concepção bastante repisada, mas nem por isso menos relevante, Antonio Candido (2010, p. 63) estabelece a arte, como uma

\footnotetext{
transposição do real para o ilusório por meio de uma estilização formal, que propõe um tipo arbitrário de ordem para as coisas, os seres, os sentimentos. Nela se combinam um elemento de vinculação à realidade natural ou social, e um elemento de manipulação técnica, indispensável à sua configuração.
}

Em outras palavras, como uma atividade humana e automotivada, que engendra uma forma estética ao transpor um material sensível da realidade, tomada aqui em acepção ampla como "natural ou social", para o fictício - ou "ilusório". Forma que, no caso 
específico da arte definida como literatura, constitui-se como enunciado verbal que se desdobra em superfície textual na obra literária.

Ora, uma vez que a ordenação de elementos tão diversos em sua (i)materialidade de coisas, seres, sentimentos, etc., não se faz possível na dimensão mais exígua da palavra, não sem a perda de toda a sua riqueza cognitiva e fenomenológica (BARTHES, 1996), é de se esperar que um terceiro componente assuma o papel dessa mediação representativa. Nesse contexto, o imaginário desponta como peça fundamental do processo transpositivo que determina o "ilusório" no âmbito da literatura, pois é somente por meio de sua atividade refrativa que os elementos auferidos na realidade podem adquirir uma forma distintiva de existência no interior do texto literário.

Espontâneo, fluido e desordenado, o imaginário humano se define antes como u Sartre (1986) -, capaz de articular os diversos segmentos da realidade material e objetiva em imagens de natureza imaterial e subjetiva. Nessa perspectiva, embora a constructo neuropsíquico assim produzido se desvele como forma autônoma, a sua existência não saberia escapar à natureza própria à imagem: irreal, porque intangível em sua substância abstrata (ou consciente); e referente, dada a materialidade que lhe incitou a origem (SARTRE, 1986). De onde resulta uma existência de caráter ambivalente: "presente [na consciência], mas, ao mesmo tempo, fora de alcance" da sensopercepção humana (SARTRE, 1986, p. 240); autônoma, porém tributária da realidade objetiva que a circunscreve.

Assim, quando se retorna ao âmbito da literatura, o substrato que constitui o "ilusório" de suas formas artísticas encontram, no enunciado verbal, uma maneira de condensar as próprias imagens na densidade semântica da palavra, de modo que o imaginário se vê, afinal, realizado em forma e finalidade estéticas (LIMA, 2007). Ao passo que a complexidade vivencial do ser humano diante do próprio mundo pode preservar seus contornos, ainda que de maneira refigurada, no interior dos fragmentos de realidade investidos na tessitura imaginária do texto.

\section{FICÇÃO LITERÁRIA E O MUNDO COMO SE}

Ainda que disposto de maneira distinta, esse parece ser o mesmo itinerário teórico percorrido por Wolfgang Iser (2002), no intuito de definir o procedimento pelo 
qual o dado real e o produto do imaginário se veem entremeados nos interstícios do enunciado - procedimento que encontra manifestação contundente no âmbito da ficção literária. Segundo o teórico alemão, a aplicação dos mecanismos da ficção à literatura se daria por uma operação simultânea de "irrealização do real e realização do imaginário", à semelhança do já descrito até aqui (ISER, 2002, p. 960). Em termos largos, isso equivaleria a dizer que embora o imaginário seja capaz de figurar "uma realidade de todo reconhecível" no interior de uma narrativa, essa mesma realidade não poderia escapar ao "signo do fingimento" que é próprio à ficção (ISER, 2002, p. 973).

Como resultado dessa operação voluntária de fingimento, Iser (2002, p. 973, grifo nosso), propõe que "o mundo impresso na obra literária seja posto em parênteses, para que se entenda que o mundo representado não é o mundo dado, mas que deve ser apenas entendido como se o fosse". Nesse processo, a obra adquire antes a natureza de um plano de intersecção entre o mundo ficcional e o mundo real - entre texto e contexto; uma intersecção mediada pela linguagem imaginativa, mas sempre em caráter aproximativo, implícito na condição do como se ficcional. De onde se enseja que se o mundo literário "não é substituível pelo real a que se refere", é justamente essa posição de entremeio que garante ao produto do "imaginário sua significação, e, mais ainda, a condição de sua experimentabilidade" como entidade dotada de existência simbólica (ISER, 2002, p. 982-983). Ou ainda, a sua experimentação como um pequeno mundo: "finito, fechado, muito semelhante ao nosso, embora ontologicamente mais pobre", capaz de animar o leitor a "explorá-lo em profundidade" nas suas (des)semelhanças com o próprio mundo (ECO, 2009, p.89).

Dessa forma, ao instituir um enunciado verbal que se configura como um análogo imaginativo do real, a ficção literária termina por desdobrar uma situação comparativa que depreende de si a existência necessária de ao menos um par de consciências - autor e leitor -, que é responsável por ensejar e concretizar a sua experimentação como forma artística. De maneira concorrente, visto que ambas as partes têm suas atividades - produção e recepção - delimitadas pelas contingências de seu momento histórico, não é de se admirar que a ficção impressa no texto se veja permeada por convenções predeterminadas na história e partilhadas, em graus diversos, por autor e público (ISER, 2002). 
Em roupagem mais simples, seria o caso de afirmar, portanto, que "para nos impressionar, nos perturbar, nos assustar ou nos comover até com o mais impossível [ou irreal] dos mundos, contamos com o nosso conhecimento do mundo real", no que esse conhecimento tem de mais complexo e diversificado (ECO, 2009, p.89). De onde se infere que no processo de (de)codificação dos sentidos que perfazem a obra literária, tanto o autor quanto o leitor se deparam com correlações variadas - linguísticas, simbólicas, socioculturais, etc. -, que são determinantes para concretizar tanto a representação quanto o contraponto desses mundos possíveis.

Ainda nessa direção, mas num passo mais largo, a considerar, como pontua Costa Lima (1980, p. 70), que “em uma sociedade complexa, constituída por classes com oportunidades socioeconômicas e culturais desiguais, não há um único, mas inúmeros sistemas de representação", é de se esperar que cada um desses sistemas seja capaz de moldar as relações entre o homem e o mundo de maneira relativamente singular. Assim, quando tomadas em conjunto, essas instâncias - sujeitos, correlações, representações e sistemas - terminam por configurar um sistema simbólico mais vasto, a partir do qual os aspectos mais variados da realidade objetiva podem adquirir sentido e interpretação diversos.

Imersas que estão nesse panorama, não é de se espantar que certas implicações despontem no horizonte imediato da literatura e de sua modalidade ficcional. Ora, uma vez que a obra literária se desdobra aqui como sistema de representação de um mundo em parênteses, parece evidente que a sua produção não saberia escapar à dinâmica histórica e sociocultural que subjaz ao sistema simbólico vigente (CANDIDO, 2010). Nesse contexto, cada autor se vê impelido a selecionar seu material fabulatório "dos sistemas contextuais preexistentes, sejam eles de natureza sociocultural ou mesmo literário" (ISER, 2002, p. 960), num movimento que pode se adequar a ou transgredir as premissas ideológicas e estéticas de seu momento histórico.

Em outras palavras, isso equivaleria a dizer que todo ato subjetivo de criação se vê, pois, às voltas com "a admissão, a presunção ou a premonição de uma norma estética", num paradigma que poderia ser resumido ao axioma de que "inexiste poeticidade em si mesma", alheia às relações entre o sujeito e a realidade objetiva (LIMA, 1980, p.76, grifo do autor). Ao passo que, nesse mesmo paradigma, a literatura se torna o lugar de uma dialética que oscila, segundo Antonio Candido (2010, p. 32), 
entre uma arte de agregação e de segregação, preocupadas, respectivamente, em “incorporar-se a um sistema simbólico vigente utilizando o que já está estabelecido como forma de expressão de determinada sociedade"; ou "renovar o sistema simbólico [e] criar novos recursos expressivos". Dialética esta que, fundada na relação entre literatura e contexto simbólico, enseja toda uma diversidade de poéticas e teorias literárias que, em menor ou maior grau de institucionalização, determinaram tanto a práxis quanto a recepção literária de seu tempo.

\section{DAS CATEGORIAS E LEITURAS - "A TEORIA DO ROMANCE" DE LUKÁCS}

Uma ilustração importante dessa dialética da produção literária pode ser encontrado na análise, empreendida por Lukács, das diferentes condições históricas e filosóficas que motivaram a humanidade a criar o romance como forma literária em contraponto à epopeia, narrativa própria à antiguidade clássica. Para o autor húngaro, em sua Teoria do Romance (2009), a épica clássica da epopeia estaria constrita a retratar um mundo no qual as vicissitudes da subjetividade são predeterminadas de acordo com a unidade estabelecida pelo entendimento mítico da realidade - um entendimento auto-dado, harmônico e imanente. Em contraponto, o romance surgiria como forma própria a um momento em que "tanto as partes quanto o todo de um tal mundo exterior escapam às formas de configuração imediatamente sensível": quando as relações entre o sujeito e seu contexto deixam de ser incontestes e imediatas, e as formas literárias têm sua origem em relação "à interioridade vivenciadora dos homens que nela vagam" e "ao olhar contemplativo e criador da subjetividade expositiva do artista” (LUKÁCS, 2009, p. 80).

A despeito, no entanto, das maneiras distintas de considerar as relações entre o indivíduo e o seu mundo, "epopeia e romance [...] não diferem pelas intenções configuradoras, mas pelos dados histórico-filosóficos com que se deparam para a configuração" (LUKÁCS, 2009, p. 55). Nisso, ainda que por contraste, nenhuma das duas seria capaz de escapar ao intento de configurar uma realidade que entremeia em si, a um só tempo, a dualidade sujeito-objeto, visto que a assunção ou refutação enfática de um depreende o outro como avesso de um mesmo processo produtivo. Isso porque 
ainda que o autor derive a forma literária de sua experiência subjetiva imediata, esta só se constitui sobre o esqueleto social que a encerra. Do mesmo modo, seja a individualidade um mero veículo para a manifestação de um a priori objetivo e essencialista, seu papel predeterminado na economia simbólica do mundo é fundamental para a constituição de uma totalidade imanente sem fissuras.

Desta feita, não seria equivocado afirmar, em juízo derivativo, que se não há forma literária sem um ato idiossincrático de criação imaginativa, este não se restringe a descerrar de maneira unilateral nem os meandros de uma subjetividade autocêntrica, nem as minúcias de uma objetividade completamente desgarrada do sujeito que escreve. Uma concepção que reitera, decerto, a noção da literatura como "sistema simbólico, por meio do qual as veleidades mais profundas do indivíduo se transformam em elementos de contato entre os homens, e de interpretação das diferentes esferas da realidade" (CANDIDO, 2000, p. 23).

Além disso, se "a epopeia dá forma a uma totalidade da vida fechada a partir de si mesma, [e] o romance busca descobrir e construir, pela forma, a totalidade oculta da vida" (LUKÁCS, 2009, p. 60), a universalidade de ambas as concepções - totalidade e vida - não poderia escapar às contingências que as determinam, historicamente, de maneira diversa. Ao cabo, se por um lado a análise de Lukács parece corroborar tanto o axioma barthesiano já enunciado, quanto a dinâmica subjacente à constituição do imaginário-ficcional; de outro, ela aponta para a historicidade do processo criativo, fator que não se isenta de ramificações importantes para o estudo da literatura como fenômeno artístico.

A primeira delas concerne à possibilidade de construção de diferentes historiografias da produção literária. É nesse sentido, por exemplo, que ao pressupor "que as obras se articulam no tempo, de modo a se poder discernir uma certa determinação na maneira por que são produzidas e incorporadas ao patrimônio de uma civilização", Candido (2000, p.29) não faz mais do que suscitar a possibilidade de definir panoramas críticos distintos de acordo com critérios produtivos que variam em termos históricos e/ou territoriais. Nessa acepção, seria possível reunir e categorizar conjuntos de produções semelhantes, singularizados em seus respectivos pares autorobra, em linhas diacrônicas: sejam eles de uma época, de uma geografia ou de um 
recorte cultural específico. Este é o cerne, aliás de toda uma disciplina como a historiografia literária.

Em contrapartida, como esforço próprio de recepção crítica, toda espécie de categorização do fenômeno literário se vê necessariamente às voltas com as implicações ideológicas do par dialético adequação e transgressão que constituem o sistema simbólico e a norma estética de um determinado recorte histórico. De onde se enseja uma segunda implicação, entrevista, apenas, na discussão sobre o imaginário-ficcional: a importância da leitura.

A considerar que o caráter comunicacional é fundamental para a concretização da literatura como forma artística, não é de se admirar que a leitura se desvele, a um só tempo, como o ponto de confluência desse processo dialético e a origem de seus desdobramentos críticos. Ora, é bem-sabido, desde o advento de uma estética do efeito e da recepção, que uma obra literária "não se pode considerar realizada, a não ser no estrito sentido material, senão ao ser acolhida pelo leitor", pois "em si mesma, em sua textualidade, a obra é apenas um quadro de indicações que só se ativam pela [sua] participação ativa" (LIMA, 1980, p. 77). Como resultado, o texto literário teria o potencial de adquirir "uma relação indireta com realidades importantes para o leitor e, através destas, com todo seu universo como complexo de valores" (MUKAROVSKY, 1983, p.64 apud LIMA, 1980, p. 78). De modo a suscitar um espaço de reflexão capaz de abranger tanto os valores impressos no mundo ficcional, quanto as relações que os valores próprios ao leitor mantêm com o mundo objetivo.

É dessa forma, ou seja, por meio da constituição dessa espécie de plano intersubjetivo, que a obra literária se mostra capaz de imprimir "sobre os indivíduos um efeito prático, modificando a sua conduta e concepção do mundo, ou reforçando neles o sentimento dos valores sociais" (CANDIDO, 2010, p. 30). Um efeito que pode se desdobrar de forma diacrônica, visto que a perenidade de certas obras a carregam por realidades trans-históricas. Ao passo que a literatura se vê, ao cabo, revestida da "faculdade de remeter a realidades totalmente diversas da que representa diretamente e a sistemas de valores distintos daquele que ela saiu e sobre o qual foi construída" (MUKAROVSKY, 1983, p.64 apud LIMA, 1980, p. 78).

Em termos mais objetivos, se uma obra literária pode ir muito além dos limites sincrônicos de sua recepção e alcançar leitores em épocas e contextos diversos, isso 
ocorre por um esforço produtivo que, apesar de contingente, pode transcender o seu próprio momento histórico. Não obstante, o potencial inerente a tais esforços, essa transcendência só pode se concretizar com a instituição de planos de interação intersubjetiva a partir dos quais leitores de momentos históricos distintos, seriam "forçado[s] a revelar aspectos de si mesmo no intuito de experimentar a realidade que", por ser impressa e imaginária, "é diferente de sua própria [realidade]" (ISER, 1974, p. 281). Para quem sabe assim, a partir do próprio esforço hermenêutico diante do outro de natureza literária, compreender melhor a sua própria situação no mundo.

Nesse contexto, práxis e recepção crítica se entremeiam na compreensão do fenômeno literário, não seria insensato considerar categorias específicas, como literatura nacional, literatura feminista ou pós-colonial e a mitopoética, de maneira ambivalente em sua pertinência teórica e nos diferentes momentos de sua caracterização conceitual. Para além, no entanto, de desvelar a complexidade inerente à questão, a breve análise dessas esferas conceituais não tem outro intento que não o de demonstrar o quanto tais categorias se veem permeadas pelo mesmo esteio teórico que relaciona literatura e ficção, imaginário e realidade.

\section{LITERATURA OU LITERATURAS? NACIONAIS, MINORITÁRIAS, MÍTICAS.}

Em suas origens, o conceito de literatura nacional remete, como desdobramento estético e ideológico de noções como nação, identidades nacionais e culturais, a dois momentos importantes na história do ocidente: à instituição do Estado moderno e ao movimento estético do Romantismo (VIEIRA, 2010). Em conjunto, essas noções foram determinantes para o funcionamento das sociedades ocidentais em âmbitos econômicos, políticos e culturais, por longa data, e continuam a permear, em graus diversos, o ideário comum até agoras.

Diante da amplitude desse paradigma, não é de se espantar que a produção e a recepções literárias terminassem por se adequar às premissas de seu projeto ideológico e sociocultural, de sorte que à literatura importasse antes "a nacionalidade do escritor, a língua em que ele constrói sua obra e, principalmente - e esse é conceito puramente Romântico -, a cor local” (VIEIRA, 2010, p. 6). Nessa acepção, as fronteiras 
geopolíticas e linguísticas se tornam parâmetros críticos de interação e distinção entre obras e autores, ao passo que toda a complexidade humana e artística inerente aos mundos possíveis da ficção se vê compreendida de forma bastante homogênea, sob a égide da nacionalidade.

Em contrapartida, uma vez instituído como norma estética, esse paradigma não saberia escapar à reiterada dialética entre adequação e transgressão que subjaz ao seu sistema simbólico. Relação que, amparada na ascensão de novas premissas socioculturais e ideológicas, pode desvelar as incongruências de qualquer norma ou paradigma vigentes. É nesse sentido, portanto, que no advento de um contexto epistemológico como o desenvolvido após as duas grandes guerras - contexto no qual, segundo Lyotard (1984), as metanarrativas de Estado, nação e identidade enfrentam o próprio ocaso teórico e cultural -, a noção de literatura nacional se depara com o descrédito crítico, com o anacronismo de seus elementos conceituais e cede lugar a novas poéticas e historiografias literárias.

Assim, à medida que as fronteiras territoriais e linguísticas se dissolvem na relativização de seus limites, é possível entrever a assunção correlata de discursos socialmente marginalizados dentro da pretensa univocidade identitária e cultural de um país ou território bem delimitado. De modo que a literatura deixa de ser entendida como "um argumento no conflito do prestígio cultural, ou como um bem no comércio exterior, ou, até mesmo, como um indicador da psicologia nacional” (WELLEK, 1994, p. 131, grifo do autor), para assumir-se como forma de expressão heterogênea e idiossincrática.

Nessa perspectiva, a literatura nacional cederia lugar a recortes distintos de produção e crítica literárias, calcados em aspectos que extrapolam as fronteiras nacionais e, a despeito da especificidade, englobam condições socioculturais semelhantes, espalhadas pelo mundo: a etnia, as questões de gênero, as diversas formas de exploração humana. Cederia espaço, afinal, a "literaturas" de caráter ambivalente literatura negra, indígena, feminista, pós-colonial, etc. Ambivalentes, pois, ao mesmo tempo em que concedem voz e discurso a grupos marginalizados, sua normatividade heteróclita se vê sujeita ao risco de submeter-se tanto à ideologização de uma norma social e estética, quanto à homogeneização das relações entre o sujeito e o mundo contidas na obra literária, sob a égide, agora, de diferentes eixos temáticos. 
Parece evidente, portanto, que as duas maneiras de considerar a literatura - em termos de nação ou de grupos socioculturais - vinculam-se estreitamente a certos paradigmas históricos e daí derivam sua pertinência teórica, sem escapar ao esforço crítico diacrônico que as engendrou em um primeiro momento. Ou seja, uma vez que a humanidade e suas construções artísticas estão em constante mudança, as categorias literárias também se enquadram num processo dialético que não encontra, , uma síntese harmônica e definitiva.

Nisso, se por um lado uma narrativa ou um poema seriam incapazes de alcançar a totalidade da vida por meio de sua forma, ou da intenção de seu autor, não sem incorrer em possíveis deficiências ou anacronismos; de maneira semelhante, à crítica literária não parece possível estabelecer uma sistematização teórica capaz de abarcar universalmente a literatura como fenômeno. Ambos referem, necessariamente, a um determinado recorte de realidade que é sociocultural e histórico. Dessa maneira, não obstante o alcance crítico das literaturas nacionais, étnicas, de gênero, pós-coloniais, etc. como modo de compreensão de uma determinada práxis literária, dois aspectos parecem escapar ao seu alcance: uma compreensão universal do fenômeno literário e de seu caráter trans-histórico.

Aqui, a obra de Lukács (2009) parece fornecer um último recurso elucidativo a essa pretensão, que subjaz às diversas formas de produção, crítica e historiografia literárias. Em uma acepção decerto nostálgica ou utópica, o axioma lukacsiano (2009, p.60) que vincula as formas literárias à necessidade de se retratar (epopeia) ou reconstituir (romance) esteticamente o sentido próprio à totalidade da vida, remete, diretamente (épica clássica) ou em contraponto (épica moderna), a uma cosmologia ou disposição mental específica. Em ambas, no entanto, o mito, caracterizado por Eliade (1957, p. 22, grifo do autor) como uma "história verdadeira, que se passou no início do Tempo e que serve de modelo ao comportamento dos humanos", institui-se como forma absoluta e originária de sentido para os aspectos mais primordiais do mundo.

Seria essa então uma espécie de unidade comum à literatura em sua obstinação em dar conta do real, que se desdobra por toda a história? Essa parece ser a concepção de estudiosos como Trousson (1981, p. 122), para quem a substância mítica "preserva e restitui através de suas inumeráveis transmutações, algumas constantes, algumas preocupações fundamentais, em um dito, algo de essencial à natureza humana" no 
interior das formas literárias. De modo que, ao cabo, o mito seria um substrato narrativo comum à humanidade, no que ele pode aceder a questões que permeiam toda a sua história e em seu potencial de ser revisitado de maneira diversa como matéria bruta para a produção literária.

Em contrapartida, ainda que se constituam como "organizações simbólicas que fazem vibrar as cordas sensíveis de todos os seres humanos, ou de muitos dentre eles" (SELLIER, 1984, p. 118), quando aproveitados pela literatura, os mitos não deixam de ser um material poético e/ou narrativo que, não obstante, o seu potencial trans-histórico, estão sujeitos às contingências socioculturais que modulam suas atualizações. Dessa forma, não seria imprudente afirmar que

\footnotetext{
cada época constitui uma mitologia particular, própria a exprimir suas preocupações, a refletir suas aspirações e inquietudes; o tema [ou mito], sempre proteiforme e suscetível à renovação, toma menor ou maior importância de acordo com as condições de adaptação de sua estrutura interna às exigências do pensamento novo. (TROUSSON, 1981, p. 98)
}

Assim, se no caso da antiguidade clássica uma normatividade poética se estende, como já visto, à subjetividade de maneira que os mitos concedem sentido à vida e à obra literária de maneira insciente e inconteste, o mesmo não poderia ser dito do seu emprego em todos os períodos estéticos da literatura ocidental. Pelo contrário, à medida que o sujeito assume cada vez mais a posição de epicentro das preocupações literárias, o reaproveitamento da substância mítica se torna antes uma tentativa artística de reconstituir, de maneira refratada pela subjetividade em contexto, um sentido para vida e para a humanidade. Tentativa que se estende, como experiência estética, às incontáveis formas de fruição e reflexão crítica, inerentes à história de leituras de uma obra literária.

Retoma-se aqui, afinal, todo o processo dialético entre a literatura e seu sistema simbólico vigente, processo que irá permear e refigurar as diversas revisitações dos mitos - Ulisses e a astúcia, Édipo e o incesto, Fausto e a ambição, Don Juan e a sedução, para citar exemplos esparsos - de acordo com os matizes ideológicos e socioculturais de cada época e autor, em sua obra literária. Nisso, se é possível tratar de uma mitopoética, semelhante às literaturas nacionais e minoritárias, aquela não poderia, a exemplo destas e a despeito de um maior potencial trans-histórico, compreender de maneira universal o fenômeno literário. Ao menos não sem se ver 
diluída toda a complexidade estabelecida no processo idiossincrático de configuração imaginária e ficcional do real, que perfaz a literatura em geral.

Ao fim, não seria insensato revisitar a premissa de partida considerando toda a argumentação proposta, dado que a obstinação em dar conta do real, considerado em toda sua complexidade geopolítica, sociocultural e mítica, talvez seja o impulso criativo que não deixa de imprimir no imaginário humano a necessidade de continuar a produzir enunciados ficcionais e obras literárias no curso da história. Por outro lado, como avesso de um mesmo processo, a busca por um sentido próprio às vicissitudes de uma subjetividade imersa inexoravelmente no real parece provocar a humanidade à constante releitura de si, do outro e do mundo, entretecidos na malha textual de um verso ou de uma narrativa. De resto, como única conclusão possível, talvez essa seja a única forma de compreensão universal da literatura: a de um fenômeno humano que busca desvelar, por meio da linguagem, o que é propriamente humano.

\section{Referências}

BARTHES, Roland. Aula. São Paulo: Ed. Cultrix, 1996.

CANDIDO, Antonio. Formação da Literatura Brasileira. Belo Horizonte: Ed. Itatiaia Ltd., 2000.

CANDIDO, Antonio. Literatura e Sociedade. Rio de Janeiro: Ed. Ouro sobre Azul. 2010.

ECO, Umberto. Seis Passeios pelos Bosques da Ficção. São Paulo: Cia. das Letras, 2009.

ELIADE, Mircea. Mythes, Rêves et Mystères. Paris: Gallimard, 1957.

ISER, Wolfgang. The Reading Process: A Phenomenological Approach in The Implied Reader. London: The John Hopkins Press Ltd., 1974, pp. 274-294

ISER, Wolfgang. Os atos de fingir ou o que é fictício no texto ficcional in Teoria da literatura em suas fontes, vol.II. Rio de Janeiro: Ed. Civilização Brasileira, 2002, pp. 955-987.

LIMA, Luiz Costa. Mímesis e Modernidade. São Paulo: Graal, 1980.

LIMA, Luiz Costa. Trilogia do Controle. Rio de Janeiro: Ed. Topbooks, 2007.

LUKÁCS, Georg. Teoria do Romance. São Paulo: Ed. 34, $2^{\text {a }}$ Ed., 2009. 
LYOTARD, Jean-François. The postmodern condition: a report on knowledge. Minneapolis: University of Minnesota Press, 1984.

SARTRE, Jean Paul. L'Imaginaire. Paris: Ed. Gallimard, 1986.

SELLIER, Philippe. Qu'est-ce qu'un mythe littéraire? In: Littérature, №55, 1984. La farcissure. Intertextualités au XVIe siècle. pp. 112-126.

TROUSSON, Raymond. Thèmes et mythes: Questions de méthode, Bruxelles: Editions de l'Université de Bruxelles, 1981.

VIEIRA, Anco Márcio Tenório. A propósito do conceito de literatura nacional. Revista Labirinto, Feira de Santana, n. 8, pp. 1-15, 2010.

WELLEK, René. A crise da literatura comparada in Carvalhal, T. F. et Coutinho, E. F. (orgs.). Literatura Comparada. Textos Fundadores. Rio de Janeiro: Ed. Rocco, 1994. pp. 120-132.

Recebido em: 31/05/2019

Aceito em: 28/05/2020 